\title{
A LIVE ACADÊMICA EM PERSPECTIVA BAKHTINIANA: REFLEXÕES SOBRE GÊNERO DISCURSIVO E ALTERIDADE
}

\author{
ACADEMIC LIVE FROM A BAKHTINIAN PERSPECTIVE: \\ REFLECTIONS ABOUT DISCURSIVE GENRE AND ALTERITY
}

DOI 10.20873/uft2179-3948.2021v12n2p408-429

Guilherme Brambila ${ }^{1}$

Resumo: Este artigo tem o objetivo de propor um debate sobre as dimensões formais, linguísticas e discursivas da live acadêmica na perspectiva das relações dialógicas que nela se estabelecem. A partir da compreensão da live como um gênero discursivo que vem se estabelecendo exponencialmente nas interações intersubjetivas contemporâneas. A ancoragem teórico-filosófica escolhida como panorama de observação está centrada nos postulados do Círculo de Bakhtin, com atenção específica ao conceito de gênero do discurso. Por meio de uma análise de base dialógica e indiciária (GINZBURG, 1986) de comentários em uma live acadêmica da Abralin (Associação Brasileira de Linguística), é possível afirmar que o contexto digital e suas possibilidades de voz alteritária dos participantes dão outras dimensões ao gênero discursivo, sendo inviável a afirmação de que a live é unicamente uma transposição virtual da conferência acadêmica presencial.

Palavras-chave: Live acadêmica; Gênero discursivo; Alteridade.

Abstract: This paper aims to propose a debate on the formal, linguistic and discursive dimensions of academic live from the perspective of the dialogical relations that are established in it. From the understanding of live as a discursive genre that has been establishing itself exponentially in contemporary intersubjective interactions. The theoretical-philosophical anchorage chosen as the observation perspective is centered on the postulates of the Bakhtin's Circle, with specific attention to the concept of discourse genre. Through an analysis of dialogical and indiciary basis (GINZBURG, 1986) of comments in an academic live of Abralin (Brazilian Association of Linguistics), it is possible to affirm that the digital context and its possibilities of alterative voice of the participants give other dimensions to the genre, being impossible to affirm that the academic live is simply a virtual transposition of the face-to-face academic conference.

Keywords: Academic live; Discourse genre; Alterity.

\footnotetext{
${ }^{1}$ Mestre em Linguística pela Universidade Federal do Espírito Santo. Doutorado (em andamento) em Linguística na mesma instituição. E-mail: guilhermebrambilamanso@ hotmail.com. DOI: https://orcid.org/0000-0001-79785020 .
} 


\section{Considerações iniciais}

O ano de 2020 marcou a sociedade local e globalmente a partir de uma crise sanitária que atingiu instabilidades políticas, sociais e discursivas. A pandemia de Coronavírus (COVID19), bem como sua letalidade, colocou o mundo em um impasse sobre diversos assuntos, como as formas de se praticar o isolamento social, as políticas públicas para o enfrentamento da doença, a discussão acerca da priorização da saúde sobre a economia e vice-versa, os investimentos em educação remota nesse contexto, as movimentações político-governamentais e sindicais frente ao problema, dentre outras.

Ao mesmo tempo, a comunidade científica tem colocado seu foco sobretudo nas pesquisas centradas na área da saúde, na perspectiva de um combate assertivo ao caos pandêmico. Apesar da notável importância que se apresenta na discussão e promoção de trabalhos que tratem a COVID-19 sob uma perspectiva infecto-biológica, não podemos ignorar que a pandemia de Coronavírus já se apresenta como um problema que transcende a departamentalização de áreas científicas, passando a ser pauta de estudos diversos como nas ciências sociais (MARANHÃO, 2020), educação (SENHORAS, 2020), psicologia (SCHIMIDT, CREPALDI, BOLZE, SILVA, DEMENECH, 2020) etc.

Compreendemos e defendemos que há questões de língua/linguagem que atravessam todas as áreas, desde um sentido mais estrito, enquanto material de análise obtido de sujeitos da pesquisa e divulgados por sujeitos pesquisadores, até um sentido mais amplo, enquanto arena dialógica na qual práticas de existência com as alteridades se constituem de maneiras diferenciadas em virtude do que permitem os contextos de interação social vigentes, sobretudo na interface digital.

A problemática do isolamento social é também um contexto caro aos estudos da linguagem, sobretudo os de base dialógica. Se considerarmos que constituímos e somos constituídos continuamente de linguagem pela interação social, surge consequentemente a demanda de estabelecermos interação em outras esferas e por outros gêneros do discurso, de modo que possamos garantir a sobre-existência de nossas subjetividades no agir responsiva e responsavelmente (BAKHTIN, 2010) com o outro.

Além das diversas tecnologias virtuais que já estão em nossa contemporaneidade e têm sido utilizadas para estabelecer as relações de trabalho, estudos e de relacionamento no contexto de isolamento social, como os telefones celulares, e-mails, aplicativos de mensagens, redes sociais e plataformas de reunião virtual, houve um crescimento acentuado de lives. De maneira 
geral, as lives são transmissões em tempo real nas quais uma ou mais pessoas podem participar e interagir entre si, utilizando suas conexões de internet, câmeras e microfones. Paralelamente, esses sujeitos podem interagir com seus espectadores, que podem acessar essa interação no momento em que ocorre e transmitir sua reação a ela via comentários ou emojis de reação, quando habilitados pelo proponente.

Para quem acessa com frequência o site Youtube ou possui uma conta nas redes sociais Instagram ou Facebook, as lives têm sido uma constante da atual conjuntura. É possível citar uma longa lista de assuntos tratados nessas lives, que vão desde a concertos produzidos por artistas de diversos gêneros e performances, a debates acadêmicos, políticos, educacionais, entrevistas, conteúdo pessoal etc. Partindo desse cenário, encontramos um calendário robusto de lives de cunho acadêmico promovidas pela Abralin (Associação Brasileira de Linguística) com nomes importantes no cenário nacional e internacional da linguística contemporânea, como Noam Chomsky, William Labov, Sirio Possenti, Kanavillil Rajagopalan, Eni Orlandi, Carlos Faraco, Ruth Amossy, Patrick Charraudeau, para citar alguns de uma longa lista.

Em virtude dessa constância e periodicidade no uso das lives como uma proposta de interação, aprendizado e consequente divulgação de conhecimento científico, visualizamos a possibilidade de dedicar estudos a essa dinâmica social na e pela linguagem, na perspectiva de analisar suas dimensões discursivas, históricas e ideológicas.

Assim, enxergamos a necessidade desse tipo de proposição para além de um verificacionismo. Buscamos construir um percurso de análise que nos permita compreender caminhos estabelecidos pelos sujeitos na e pela linguagem na contemporaneidade, entendendo a live como materialização de uma nova virada de interação social e que pode, conforme se estabiliza histórica e socialmente, assumir enquadres próprios da especificidade contextual na qual emerge em potencial.

De maneira específica, refletiremos sobre dimensões teórico-filosóficas do gênero discursivo pelo Círculo de Bakhtin, que serão o norte de toda a discussão. A partir das proposições do Círculo sobre como o gênero é estabelecido socialmente nas relações dialógicas de sujeitos histórica e socialmente situados, buscaremos não só suscitar perspectivas atualizadas à área de estudos, mostrando como os postulados teóricos ainda se realizam na contemporaneidade.

Seguidamente, pretendemos situar brevemente o que é a live, especificando seu contexto histórico e interfaces de caráter técnico. Atrelado a essa explanação, utilizaremos um exemplo de live transmitida pela Abralin como nosso contexto de interação concreto, a fim de 
movimentar uma discussão que se concentre em compreender práticas com a linguagem específicas do contexto de pandemia, que podem se manter e se estabilizar mesmo após o atual cenário.

Como afirmado anteriormente, existem lives que abordam diversos temas e que objetivam propósitos variados. Sendo assim, concebemos como apropriado encarar as lives acadêmicas da Abralin como indícios (GINZBURG, 1986) que nos permitem rastrear uma prática específica com e na linguagem. Ao mesmo tempo, esses rastros nos movem para uma discussão ampla e necessária, concentrada nos percursos requeridos pela contemporaneidade em nossas relações intersubjetivas. Afinal, para quais direções estamos indo?

\section{Gêneros do discurso, dimensões teóricas e suas práticas no contexto acadêmico}

O objetivo desta seção é traçar alguns parâmetros acerca do gênero discursivo, pensando-o desde sua concepção no Círculo até sua realização no contexto de interação acadêmica contemporânea. Apesar de que quando pensamos em gêneros do discurso fazemos uma rápida recuperação aos do âmbito da escrita, dedicaremos atenção à discussão de gêneros orais, como a comunicação acadêmica, que requerem um olhar apurado para que não façamos confusões epistemológicas, conforme é alertado por Travaglia et al (2013, p. 5):

\footnotetext{
O suporte do gênero oral não pode ser visto como a fala, porque esta é a própria língua usada oralmente. Evidentemente os gêneros orais são construídos com a língua falada e terão características dessa que podem ser específicas de um gênero ou meramente da língua falada e comuns a todos os gêneros orais. Portanto, podem ser considerados gêneros orais também aqueles que têm uma versão escrita, mas que têm uma realização prioritariamente oral, usando a voz como suporte. Estariam neste caso, entre outros, gêneros tais como: conferências; representação de peças teatrais, telenovelas e filmes que têm um roteiro ou script; as notícias faladas em telejornais e no rádio que geralmente estão previamente redigidas; recontos etc.
}

Aprofundaremos mais essa questão, após tratarmos de questões basilares do gênero discursivo. As formas "relativamente estáveis" (cf. BAKHTIN, 2011), nas quais os enunciados são organizados para participarem da interação humana via linguagem, existem e se estabelecem a partir das diversas formas com as quais os sujeitos se relacionam e se percebem histórica e socialmente. Assim, uma primeira percepção que se pode construir acerca do gênero do discurso é que, além de desempenhar o papel de suporte ao texto/enunciado, sua estrutura e conteúdo dialogam constantemente com uma dinâmica não só de interface discursiva, mas também social.

Compreendemos que os gêneros do discurso, à luz do pensamento bakhtiniano, seguem o pressuposto social, histórico e dialógico da linguagem. Mesmo o signo, elemento de partida que constituirá o gênero, é uma refração dialógica do sujeito que enuncia em meio à interação 
verbal. "O emprego da língua efetua-se em forma de enunciados (orais e escritos) concretos e únicos, proferidos pelos integrantes desses ou daquele campo da atividade humana" (BAKHTIN, 2011, p. 261). Ao propor a indiscutível constituição social e histórica do enunciado, Bakhtin nos leva ao entendimento de que os gêneros do discurso, sendo "tipos relativamente estáveis de enunciados" (Ibid., p. 262), seguirão pela mesma via, tendo sua constituição na e pela interação social. Filho e Torga (2011, p. 4), ao também refletirem sobre a noção de gênero discursivo, declaram que "o que constitui um gênero é a sua ligação com uma situação social de interação, e não as suas propriedades formais”. Depreendemos, por consequência, que refletir sobre o gênero discursivo nos coloca frente a questões de caráter social, político e ideológico imersas na linguagem.

Ao revisitarmos o texto "Os gêneros do discurso", em Estética da Criação Verbal, localizamos três elementos que, para Bakhtin, são constitutivos do gênero discursivo: o conteúdo temático, o estilo e a construção composicional, que não só o estruturam, mas também estabelecem pontes dialógicas com o entorno social e com os sujeitos que o utilizam.

De acordo com Ribeiro (2010, p. 57),

\begin{abstract}
O elemento conteúdo temático, portanto, contemplaria aspectos peculiares ao sujeito, que participam diretamente da enunciação, como sua vontade, sua singularidade, conhecimentos semânticos construídos coletivamente nas práticas sociais. A dimensão individual, tratando-se particularmente do elemento conteúdo temático, não se impõe aos parâmetros reguladores do gênero eleito, como também as dimensões constituintes do gênero não condicionam totalmente as escolhas individuais. Há, sim, uma confluência das duas esferas, a individual e a do gênero, que resultará na configuração da situação enunciativa e nos seus efeitos.
\end{abstract}

A enunciação, impulsionada pela interação social, por sua vez, ocorre mediante um conjunto de avaliações próprias do sujeito às vozes discursivas com as quais tem contato, acolhendo-as e/ou repelindo-as conforme as compreende em sua subjetividade. Assim, o gênero discursivo precisa ser pensado, dentro do aspecto do conteúdo, como uma refração subjetiva do discurso dialógico do enunciador que se dá via interação histórica e social com a linguagem.

Outro componente que forma o gênero discursivo é o estilo, sendo este também de grande afinidade com a subjetividade e com as formas com que o sujeito enunciador se relaciona com o enunciado e com as situações enunciativas que provocam as enunciações. Concordamos com Puzzo (2015, p. 179), quando declara que

Sob a ótica do Círculo, o estilo abrange todos os gêneros discursivos, em graus variáveis: mais determinado e invariável nos gêneros instituídos de modo mais 
objetivo e impessoal, como a correspondência oficial ou os documentos burocráticos; e os mais variáveis, em função da infiltração da subjetividade expressiva, como os textos literários, jornalísticos ou publicitários, entre outros.

A partir dessa consideração, temos a concepção de que o estilo é um elemento particular ao sujeito frente ao gênero discursivo. Aos gêneros discursivos de atuação mais institucional como atas, ofícios, memorandos etc. - isto é, em que não convém revelar diretamente a complexidade discursiva do sujeito enunciador, o estilo é firmado pela própria dinâmica ditada por ritos institucionais. Por outro lado, aos gêneros que funcionam explicitamente em sociedade dentro da proposta de revelar o ponto de vista de alguém sobre algo, o estilo é recepcionado na refração da subjetividade em enunciados concretos do eu ao outro. Bakhtin (2011, p. 266) traz esclarecimentos pertinentes sobre como o estilo se relaciona com o gênero discursivo ao declarar que

\begin{abstract}
A relação orgânica e indissolúvel do estilo com o gênero se revela nitidamente também na questão dos estilos de linguagem ou funcionais. No fundo, os estilos de linguagem ou funcionais não são outra coisa senão estilos de gênero de determinadas esferas da atividade humana e da comunicação. Em cada campo existem e são empregados gêneros que correspondem às condições específicas de dado campo; é a esses gêneros que correspondem determinados estilos.
\end{abstract}

O que se pode compreender a partir das palavras de Bakhtin é que o estilo está constantemente rendido às demandas sociais que recaem sobre o gênero, sob a pena de provocar confusão ou falta de decoro quando não estiver alinhado ao que o gênero e a situação enunciativa requerem (principalmente aos casos de gêneros institucionais). Bakhtin também levanta uma importante reflexão a respeito da estilística (estudo do estilo) e da gramática (estudos das normas de língua), quando se posiciona a respeito da relação desses dois campos:

Pode-se dizer que a gramática e a estilística convergem e divergem em qualquer fenômeno concreto de linguagem: se o examinamos apenas no sistema da língua estamos diante de um fenômeno gramatical, mas se o examinamos no conjunto de um enunciado individual ou do gênero discursivo já se trata de um fenômeno estilístico. Porque a própria escolha de uma determinada forma gramatical pelo falante é um ato estilístico. (BAKHTIN, 2011, p. 269).

O que é perceptível na ótica bakhtiniana a respeito do estilo é que esse elemento se torna genuinamente observável sempre que a questão social for levada em consideração na prática analítica, pois é da interação que emergem movimentos definidores da forma com que o sujeito desenhará seu enunciado. 
Por fim, a construção composicional é o elemento do gênero discursivo que engloba seu formato, sendo que este existe de maneira relacional com o conteúdo. Bakhtin e Medvedev (1994, p. 222), ao defenderem que "não há conteúdo sem forma, como não há forma sem conteúdo", definem que a construção composicional não é uma parte alheia ao gênero discursivo, mas que dialoga com os demais constituintes, estruturando-o histórica e socialmente.

Maciel (2015) reflete a respeito da necessidade de não se compreender de maneira simplista a construção composicional, confundindo-a com a funcionalidade de "fôrma" do gênero.

\begin{abstract}
No limite até se poderia imaginar que a construção ou forma composicional seria uma espécie de "fôrma", um esquema espacial para a composição do enunciado, que preveria certa extensão do texto e certa disposição dos parágrafos. Entretanto, ainda que se admitisse esse conceito de forma composicional como algo próximo a uma "fôrma", seria necessário lembrar que essa "fôrma" é, antes de tudo, flexível. Isso porque são variáveis tanto a extensão de um texto (falado ou escrito) quanto sua organização em parágrafos (no caso do texto escrito). A forma composicional não existe como uma "fôrma" vazia, mas como enunciado real e único, com sua extensão e disposição gráfica própria. É ao ganhar conteúdo que a forma ganha definição. (MACIEL, 2015, p. 254).
\end{abstract}

Concordamos com Maciel e com o pressuposto bakhtiniano que não compreende o gênero discursivo de maneira compartimentada. Assim como a construção composicional existe interdependente ao conteúdo, o gênero discursivo constrói-se de maneira relacional na comunicação humana, atendendo a suas demandas interativas e transformando-se histórica e socialmente.

Ao movimentarmos a discussão para o campo da oralidade, podemos afirmar que estão instaurados na interação humana institucional e não institucionalmente os gêneros discursivos orais. Essa consolidação, além de partir e avançar discussões sobre o que se categoriza como gêneros da fala ou da escrita (MARCUSCHI, 2001), é estabelecida pelo entendimento de que práticas de oralidade são também constituintes e constitutivas das relações histórica e socialmente situadas dos sujeitos em esferas sociais variadas, sobretudo impulsionadas pelas tecnologias da informação (TICs), que têm dado cada vez mais base para que superemos o olhar mitificado sobre a oralidade ser diretamente relacionada à efemeridade.

Em muito devido às mudanças históricas decorrentes das novas tecnologias eletrônicas e digitais da comunicação e da informação, que colocaram em causa, com suas mídias, muitas dessas constatações - como a situação face-a-face da fala e a distância da escrita; a fugacidade da fala e a preservação do escrito etc. -, da década de 90 em diante, começou-se a pensar relações menos simplistas e dogmáticas entre

\footnotetext{
${ }^{2}$ No hay contenido sin forma, como no hay forma sin contenido.
} 
a fala e a escrita nas sociedades complexas e letradas. Duas posições ganharam relevo nestas discussões mais recentes:

a) a existência de um contínuo ou gradação entre fala/escrita (linguística textual, análise conversacional, teorias de gêneros textuais); e

b) a existência de relações complexas de constitutividade mútua entre fala e escrita em contextos específicos de uso (teorias da enunciação e do discurso). (ROJO, SCHNEUWLY, 2006, p. 465).

É muito comum relacionarmos os gêneros discursivos orais a práticas de didatização/escolarização para a educação básica (cf. FAVERO, ANDRADE AQUINO, 1999; SCHNEUWLY, DOLZ, 2004; AQUINO, 2015, para citar alguns), o que pode até provocar uma má interpretação de que os gêneros orais são trabalhados e discutidos proficuamente na esfera escolar por não terem versatilidade enquanto objetos de estudo em outras esferas. Em face disso, pretendemos elaborar algumas percepções no âmbito do discurso e da interação verbal, ancorados na perspectiva bakhtiniana anteriormente trazida, a fim de explicitar como os gêneros orais podem ser assumidos em sua profundidade dialógica e estabilidade relativa, sobretudo no cenário atual que tem causado seu uso exponencial.

Tomando o contexto acadêmico como nossa esfera de observação, afirmamos que gêneros orais são basilares no processo formativo e nos ritos de passagem institucionalizados pela universidade. Os exemplos são variados e atendem a naturezas de interação múltiplas, como a conferência/comunicação acadêmica, seminários, defesa oral de Trabalho de Conclusão de Curso (TCC), defesa de mestrado e doutorado etc. Partindo da experiência analítica de Rojo e Scheuwly (2006), ao proporem um percurso de estudo sobre a conferência acadêmica, compreendemos que há constituintes do gênero oral que extrapolam categorias dos gêneros discursivos de maneira geral, visto que há partes "tramadas de um discurso cujo funcionamento é conjunto e mutuamente determinado" (p. 481). Os autores trazem um dado interessante sobre haver uma abertura constitutiva no gênero oral para agregar outros gêneros em sua interface, que tanto o estabilizam quanto o relativizam na interação social, ao se referirem às redes de inter-relação dialógica que atravessam o gênero conferência acadêmica, como gêneros de natureza escrita do qual partem (texto escrito para apresentação) ou que o congregam (slides que acompanham a comunicação, interação intersubjetiva com possíveis mediadores e público).

Compreendemos que há um aspecto estabilizador nas interfaces possíveis que se agregam aos gêneros orais, visto que plataformas, como os slides, são facilitadores não só do desenvolvimento em nível tópico-textual, mas também da manutenção do conteúdo temático e do estilo aplicados a determinadas formas de relação intersubjetiva de natureza oral. Retomando a perspectiva bakhtiniana, que relaciona o conteúdo temático à singularidade do sujeito que se 
expressa no campo do enunciado, expomos o entendimento de que o suporte dado pelos materiais que guiam um gênero oral é importante enquanto preservador da conclusibilidade do enunciado (BAKHTIN, 2011) que se realiza no processo da fala e que está muito mais suscetível à intervenção do que no plano escrito.

Apesar de entendermos que os atravessamentos alteritários no processo de interação social via gêneros orais são constitutivos à subjetividade daquele que enuncia, importa mencionar que, sem uma mínima regulação ou direcionamento, essa alteridade deixa de construir a singularidade do ato e passa a conduzir o discurso para propósitos que podem alterar ou anular a própria dimensão do gênero estabelecido. A fim de propor uma ilustração do problema, a falta de um roteiro ou organização tópica que guie o gênero comunicação oral pode transpor o processo de interação entre o comunicador e seu público para outros gêneros, como o debate desregrado ou conversa cotidiana.

A forma composicional do gênero oral, assim como preveem os estudos bakhtinianos, não pode ser deslocada do conteúdo e das relações intersubjetivas que são próprias dos enunciados. Desse modo, a especificidade das relações intersubjetivas na oralidade proporciona consequentemente formas composicionais dependentes do que se constrói em cada situação de interação, dando um caráter mais relativo a esse aspecto. Dito de outra forma, mesmo que haja certos entornos oficiais em gêneros orais acadêmicos, por exemplo, que garantem a estabilização de uma forma composicional conhecida, é possível que haja circunstâncias enunciativas pontuais (que vão desde imprevistos tecnológicos à circunstância de uma pandemia) que influem sobre todos os componentes desse gênero, proporcionando-nos formas situacionais que podem se prolongar e se estabilizar ao longo do tempo, mas que também podem se encerrar naquele mesmo instante, por terem sido desenvolvidas para suprir um contexto interacional muito específico.

A partir das reflexões estabelecidas, chegamos ao contexto que está no centro de nossa análise: a live acadêmica. Devido ao contexto do isolamento social, uma das primeiras instituições a pararem suas atividades presenciais foram as escolas e universidades. Por serem espaços nos quais a aglomeração é uma constante, além serem esferas de interação com alto contato (sobretudo a escola básica), as instituições educacionais precisaram pausar seus trabalhos, ou então readequá-los ao contexto remoto, algo que tem dividido opiniões de diversos setores sociais.

Focalizando o contexto acadêmico, em meio ao caos provocado pela pandemia, cresce o uso das lives, impulsionadas por universidades e associações como veiculadoras de 
comunicações orais e debates de pesquisadores sobre assuntos relacionados (ou não) ao cenário atual, dentro de uma proposição de continuação das interações da comunidade científica. A fim de propor a compreensão das funções sociais e intersubjetivas da live, faremos uma retomada sobre sua implementação e uso no contexto digital, evocando questões discursivas que a perpassam e a colocam frente à articulação com os gêneros orais.

\section{A Live: aspectos formais e intersubjetivos em novos contextos de interação social}

As lives (ou live streaming) podem ser consideradas um recurso novo no cenário brasileiro. Apesar de sua existência preceder a pandemia, é inegável que o fluxo de uso sofreu um grande aumento, por conta das medidas de isolamento social que pró́bem concertos, aulas, congressos e outros tipos de aglomeração. Todavia, importa informar que as lives não são uma tecnologia desta década, visto que há registro de seu primeiro uso em 1993, pela banda Severe Time Damage, na Califórnia (Estados Unidos) ${ }^{3}$. No campo dos estudos científicos, encontramos trabalhos que refletem sobre a live a partir do ponto de vista do sistema da informação, porém ainda há questões não lançadas com profundidade em outras áreas, como nos estudos da linguagem, o que justifica a brevidade na recuperação bibliográfica da seção.

Diante dessa aparente lacuna de debates, trataremos nesta seção de algumas características da live e seu lugar social e histórico na vida da academia brasileira, dando enfoque ao contexto das lives acadêmicas da Abralin que será posteriormente analisado. De acordo com o site TechTudo (2020, s/p):

Live é uma transmissão ao vivo de áudio e vídeo na Internet, geralmente feita por meio das redes sociais. O Instagram, por exemplo, possui uma ferramenta que permite ao usuário fazer uma transmissão de vídeo em tempo real para os seguidores, o que também é possível por aplicativos como YouTube, Twitter, Facebook e TikTok. Usuários podem fazer comentários e deixar curtidas, além de acompanhar as atividades dos demais espectadores.

A partir do que é explicado, temos algumas características que diferenciam a live de outros gêneros: necessita de um suporte virtual (internet), estabelece-se primordialmente por linguagem visual e oral, requer que a interação seja em tempo real com os seguidores, permite interação com os interlocutores (curtidas e comentários) e se acopla a mais de uma plataforma digital/rede social, desde que essa possua em suas configurações o recurso de vídeo.

Outro aspecto da live, explicado também pelo site supracitado, é sua regulação da socialização.

Em geral, é proibido em lives: uso de drogas; transmissão de conteúdo que possa causar danos a terceiros; divulgação de plataformas concorrentes ou conteúdos com direitos autorais; conteúdos de assédio, nudez, profanidade excessiva e grosseria; propaganda política;

\footnotetext{
${ }^{3} \mathrm{Cf}$. https://www.std.org/. Último acesso em 10/06/2020.
} 
reprodução de conteúdos de TV ou similares; apologia a conteúdos sexuais, criminosos, suicidas ou políticos no geral; utilização de armas de fogo; atitudes danosas à segurança infantil; e divulgação de informações privadas. (TECHTUDO, 2020, s/p).

A partir da regulação daquilo que pode ou não ser socializado, podemos depreender que há uma compreensão histórica e socialmente construída de que as lives não podem ser encaradas como meros suportes nos quais o limite de conteúdo é mensurado quantitativamente. Por outra via, as lives são reconhecidas como espaços de interação social, no qual sujeitos se articulam e dialogam, podendo, na falta de uma diretriz, romper com alguns tratados estabelecidos em sociedade mesmo antes do advento da tecnologia digital.

É importante também refletir que o aspecto interacional da live coloca em pauta que há uma relação muito mais complexa entre o sujeito que enuncia com o (s) sujeito (s) que podem (ou não) interagir com seus enunciados. Partindo de uma percepção empírica sobre as lives, podemos afirmar que aquele que se coloca a enunciar deve considerar que poderá compartilhar seu conteúdo com um número de internautas equivalente a uma reunião de departamento, a um estádio de futebol em lotação máxima, a uma pessoa ou a ninguém.

Esse aspecto nos instiga a pensar como a subjetividade e as relações dialógicas estabelecidas entre sujeitos na interação social são fundantes na constituição de enunciados. Diferente de uma conferência acadêmica presencial em seus moldes mais canônicos (em uma sala ou auditório, com ritos de início, aplausos, contato visual com os interlocutores, perguntas ao final etc.), uma live que tenha o mesmo propósito está muito mais condicionada à presença ou à ausência de interlocutores acessando sua transmissão, podendo ter seu estilo, duração e até conteúdos modificados (a depender do nível de interatividade estabelecido pelo proponente). Enquanto na conferência acadêmica presencial essas negociações intersubjetivas são estabelecidas antes de seu acontecimento, a live requer do proponente uma reavaliação constante dessas negociações, que é dependente da permanência ou não de interlocutores que o prestigiem.

Outro aspecto que coloca a live frente a uma irregularidade inter-relacional é a variedade de formas que os sujeitos que acessam podem reagir ao que é transmitido. As reações são, de fato, muito variáveis, visto que podem se expressar verbalmente (via comentários lançados pelos internautas, quando habilitados pelo proponente), verbo-visualmente (em emojis ou figurinhas que apresentem conteúdo verbal e visual que, casados, colocam alguma avaliação sobre o que é enunciado (BRAIT, 2013)) ou também pode não expor qualquer expressão (o "silêncio", isto é, a ausência de qualquer reação sobre o que é proferido). Dentro dessa gama de possibilidades podemos incluir reações que não buscam ou não conseguem estabelecer qualquer resposta coerente com aquele que enuncia, visto que o 
campo das reações e comentários é aberto para qualquer manifestação ${ }^{4}$. Por exemplo, não há qualquer diretriz que impeça um internauta de expressar tristeza (via emojis, figurinhas ou comentários dessa natureza) em uma live que seja um show de humor, por mais que essa reação não seja esperada ou desejada pelo proponente. Queremos esclarecer com isso que as negociações interdiscursivas na live são muito tênues e relativas, quando comparadas com interações em gêneros orais fora do contexto digital.

Figura 1 - Comentários em uma Live da Abralin

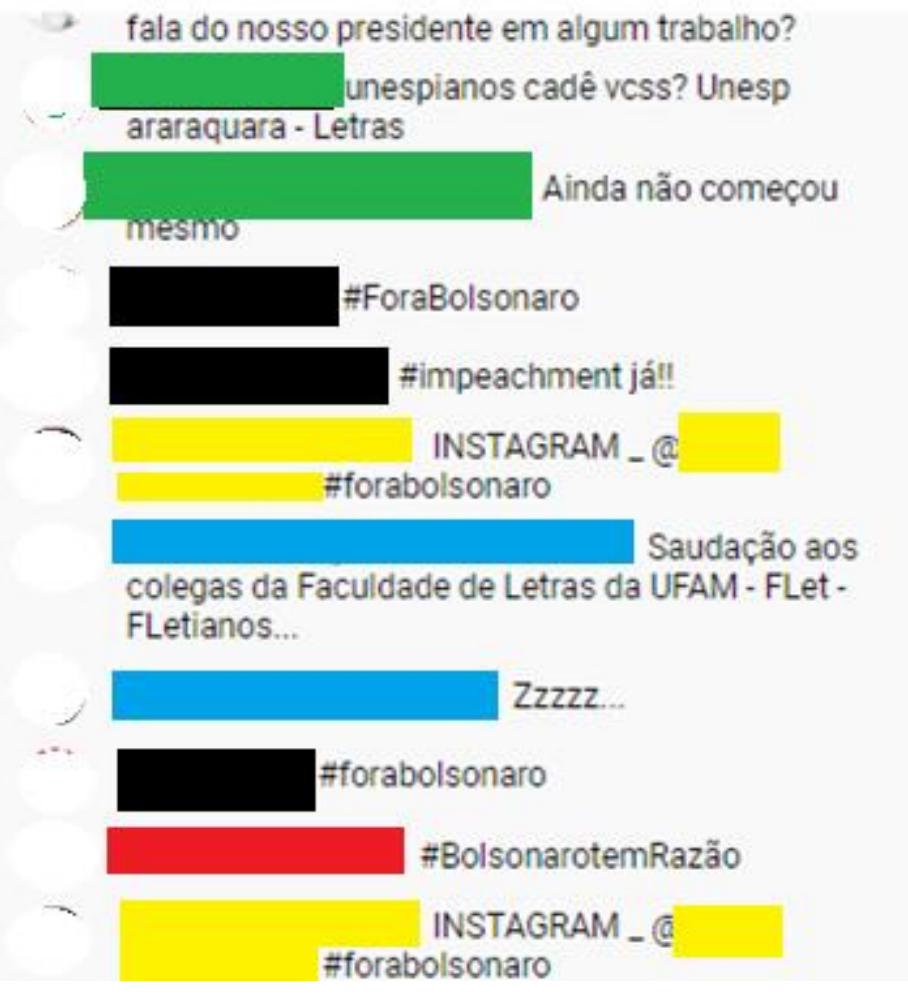

Fonte: Youtube (2020).

A imagem 1 é um exemplo concreto de nosso entendimento sobre o atravessamento discursivo desordenado das interações em uma live acadêmica, o que reordena a própria dinâmica constitutiva do gênero oral conferência científica. Ao omitirmos a identificação dos usuários, utilizamos cores distintas que nos permitem notar, apesar do pequeno fragmento, como esse tipo de interlocução nos coloca diante de uma relação muito diferente do que se compreendia por interação em esferas acadêmicas. Podemos encontrar diálogos consonantes ao que é transmitido pela live (em verde, perguntando sobre o início do evento e pelos colegas que ainda irão "chegar"), manifestações político-partidárias (em preto e em vermelho, em posições diferentes a respeito do atual chefe de Estado brasileiro), divulgação de

\footnotetext{
${ }^{4}$ Em alguns suportes há a possibilidade de selecionar comentários que ferem as políticas da plataforma e denunciálos, porém isso parte do pressuposto de que o conteúdo foi exposto livremente na transmissão.
} 
conteúdos destoantes ao tema da live (em amarelo), dentre outras manifestações (como o “ZZZ”, que pode indicar tédio ou aborrecimento).

Essa observação preliminar, que já nos concede alguns indícios (GINZBURG, 1986) sobre características técnicas e interdiscursivas da live, instiga-nos a revisitar noções de alteridade que atingem outras dimensões nesse tipo de contexto. O internauta, ao tomar o lugar de espectador da live, utiliza o espaço que lhe cabe para enunciar sobre ou com aquilo que é transmitido em tempo real. Todavia, por movimentos emotivo-volitivos próprios de sua subjetividade, esse mesmo sujeito refaz seu lugar de outro no discurso, podendo enunciar sem qualquer compromisso com o proponente. Dessa forma, é complexo acompanhar as relações dialógicas que podem ou não se estabelecer no contexto de interação da live, visto que podem assumir dimensões que fogem a qualquer linearidade.

Esse aspecto complexo e aparentemente truncado para, por exemplo, estabelecer relações de alteridade e dialogicidade entre os comentários e a live acadêmica se dá por termos um percurso já bem consolidado sobre essa análise em gêneros e enunciados que estão fora da esfera digital e que, mesmo digitalizados, ainda assumem grande parte das dinâmicas do contexto analógico. Assim, compreendemos que um passo importante nesse tipo de análise é, apesar de situarmos nossas referências nos estudos discursivos em enunciados compartilhados em gêneros de esferas majoritariamente não virtuais, reconhecer que há dinâmicas próprias que simplesmente escapam a categorizações antes tomadas como fundamentais e aplicáveis a qualquer contexto de interação verbal.

Por essa razão temos optado por constantemente assumir os dados de um estudo de base discursiva como indícios, na esteira do paradigma indiciário (GINZBURG, 1986). Assim como é pretendido para a próxima seção, observar as interações sociais na e pela linguagem como dados singulares e que refletem e refratam dialogicamente atos irrepetíveis na concretude da vida (BAKHTIN, 2010) são um caminho que tem se mostrado profícuo às pesquisas de orientação bakhtiniana. Desse modo, pretendemos nas próximas linhas observar, a partir de uma live acadêmica, rastros que se acentuam, compondo negociações intersubjetivas que estabilizam essa prática com a linguagem em comentários interativos dos interlocutores, bem como dados singulares que, orientados pela interface tecnológica ou pela eventicidade da interação, podem também abrir caminhos para repensarmos nossos próprios paradigmas analíticos.

\section{Alteridades e a live acadêmica}


Nesta seção faremos o estudo de alguns comentários realizados em uma live acadêmica promovida pela Abralin, na busca por compreender como esse formato de interação social tem se organizado no contexto e nas condições de interações contemporâneas. Nossa perspectiva de trabalho é analisar de que maneiras os comentários se diferenciam da audiência presencial, bem como se aspectos que emergem desse tipo de interação virtual podem ser compreendidos como modificadores drásticos de um gênero discursivo.

Algumas perguntas que permearão as análises são: que alteridades se constituem nos exemplos analisados? Os enunciados produzidos nesses comentários concretizam-se frente à temática e à fala das conferencistas? Quando não se articulam diretamente, é possível concebêlos como enunciados concretos?

O corpus desta análise está no canal oficial da Abralin no Youtube. Selecionamos a live A atualidade de Bakhtin: um pensador sobre a humanidade em transformação, cujas conferencistas foram as professoras Beth Brait e Sheila Grillo, em 01 de julho de 2020. Salientamos que o objetivo das análises está focado na interação, especificamente em algumas sequências de comentários que ladeiam a fala das apresentadoras, não sendo o foco do presente trabalho discorrer sobre os temas tratados na live acadêmica em questão.

O primeiro grupo de interações selecionadas apresenta quatro tipos de enunciado e consequente valoração alteritária acerca das apresentadoras, sendo marcadas em cores: apreciação valorativa positiva (amarelo), requerimento de resposta (azul), reação ao enunciado (vermelho) e reação à reação (verde).

Figura 2 - Primeiro grupo de enunciados 


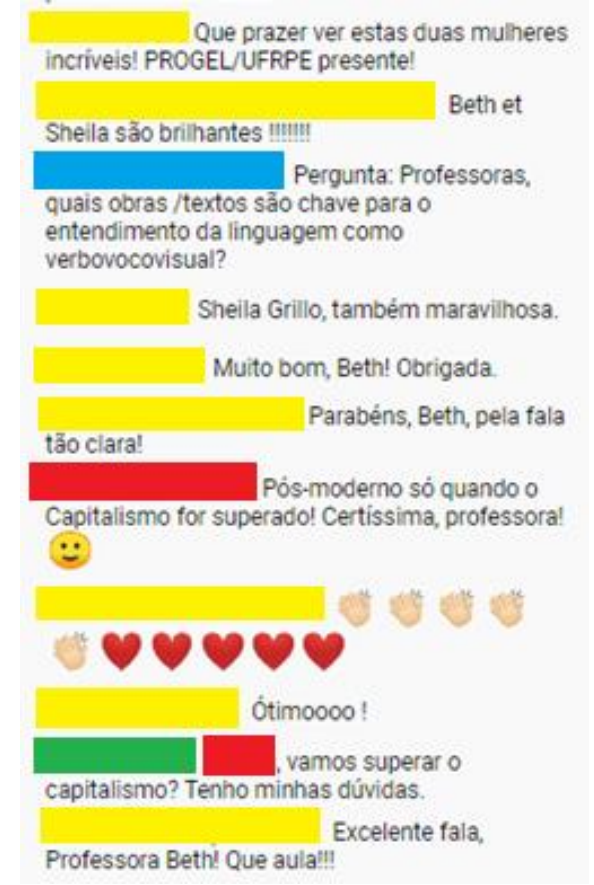

Fonte: Youtube (2020).

As apreciações valorativas positivas (em amarelo) são maioria não apenas na live acadêmica em questão, mas às lives acadêmicas de maneira geral. Apesar de nos parecerem claros os elogios transmitidos diante da importância das respectivas pesquisadoras à comunidade acadêmica, importa também salientar que essas expressões de estima também se configuram como reconhecimento do lugar que as comunicadoras ocupam na esfera de atividade humana que é a academia. Nesse sentido, é possível compreender que as apreciações valorativas positivas não apenas funcionam como reação ao conteúdo transmitido, como também desempenham um papel importante na estabilização do gênero live acadêmica, atravessando-o constantemente em demonstrações de que elas (as conferencistas) são as quem devem ser ouvidas nesse processo intersubjetivo.

Cabe ainda observar a respeito das valorações positivas que, apesar de corroborarem com a tarefa de dar destaque e estabilização ao lugar de Eu do discurso, ocupado pelas conferencistas em sua comunicação virtual, rompem com a lógica instituída pelos gêneros orais não virtuais. Se essa mesma conferência fosse proferida em ambiente presencial, as expressões elogiosas, bem como os aplausos (expressos pelos emojis de aplausos e de coração) seriam comumente externadas ao seu final, inclusive para demarcar que o que foi enunciado estabeleceu sua conclusibilidade (BAKHTIN, 2011). Todavia, a transposição dessa interlocução na esfera virtual atinge outro patamar de dinâmica, assumindo conclusibilidades múltiplas, visto que são reações contínuas ao longo de toda a live acadêmica. 
Essa mesma característica aparece no requerimento de resposta (em azul). Apesar de ser um componente comum do gênero oral, esse enunciado se manifesta ao longo da fala das pesquisadoras e não em seu final. Novamente encontramos um rompimento com a formatação canônica de uma conferência. Entretanto, notamos que tal comentário não transmite potência suficiente para interromper o fluxo enunciativo das apresentadoras, que podem ocasionalmente não ler tal intervenção por diversos fatores (excesso de comentários que se interpõem, por não visualizarem as mensagens do chat, por não avaliarem pertinência na pergunta no dado momento etc.).

Nota-se nesse caso mais uma distinção e especificidade do gênero live acadêmica. Se o requerimento de resposta atravessasse uma comunicação acadêmica presencial no meio de seu acontecimento, isso geraria uma série de tensões, como a suspensão abrupta da fala do palestrante, a interrupção e conclusão forçada do enunciada frente ao público e até mesmo o constrangimento ou tolhimento desse tipo de intervenção, por não ser convencionalmente aceita. Por todos esses efeitos, podemos considerar que haveria uma relação dialógica explícita quando esse tipo de situação ocorre presencialmente. Entretanto, na esfera virtual esse efeito não se materializa da mesma forma. Poderíamos, então, sugerir que não há relação dialógica no requerimento de resposta da live acadêmica?

As observações até aqui desenvolvidas nos movem a compreender que há, sim, relações dialógicas no requerimento de resposta em lives acadêmicas, mesmo quando não respondidas ou sequer percebidas. Porém, é necessário compreendermos que estamos diante relações dialógicas sob condições diferentes, imersas em uma aparente não territorialidade do enunciado concreto. Concebemos como aparente não territorialidade em virtude do leque de possibilidades dessas intervenções se endereçarem ao enunciado das conferencistas concomitantemente à suas falas. Ao mesmo passo, essa intervenção se demarca em uma coletividade de espectadores, coabitando alteritariamente junto aos demais comentários do painel. Criam-se, inclusive, chances de tal requerimento não encontrar seu destino na interlocução com as conferencistas, mas com outros sujeitos presentes na situação interativa.

As afirmações realizadas no parágrafo anterior podem ser percebidas de maneira prática na reação ao enunciado (em vermelho) e na reação à reação (em verde). Nos dois casos, percebemos mais uma vez um tipo diferente de interlocução com o que é transmitido pelas comunicadoras (vermelho), mas que atinge direta e efetivamente outro espectador presente virtualmente na live (verde) que se põe a questionar a reação. Notamos nessa dinâmica que o papel alteritário dos comentários na live acadêmica transcende a modelização, ramificando-se. 
Ademais, os comentários em questão nos mostram uma potencial volatilidade alteritária na live acadêmica, visto que o outro assume turnos muito efêmeros. O espectador assume lugar de outro e reage ao enunciado das professoras (vermelho), porém, sem qualquer situação previamente consentida ou instituída, esse sujeito entra no diálogo de outro participante (verde), que toma seu enunciado como ponto de partida para a sua enunciação, não havendo qualquer impedimento de que outros participantes se agrupem e questionem a interação instituída naquele espaço. Compreendemos tal ocorrência como facilitadora à volatilidade aparente do gênero live acadêmica como um todo, principalmente por sua possibilidade de abrir constantemente novas tensões (não necessariamente imbricadas) ao ponto de partida contido no enunciado das comunicadoras, adquirindo caminhos próprios.

Para a análise seguinte abordaremos outros dois acontecimentos alteritários em comentários na live das professoras Beth e Sheila: o pedido de bibliografia (em rosa) e o pedido de orientação (em laranja).

Figura 3 - Segundo grupo de enunciados

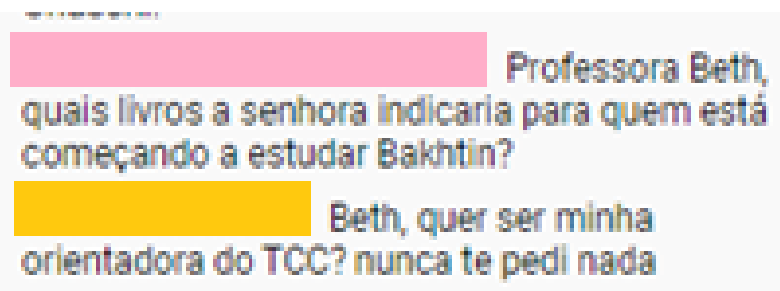

Fonte: Youtube (2020).

Apesar de haver aspectos comumente compartilhados com os outros enunciados, como o atravessamento alteritário que não corresponde aos ritos do gênero oral presencial e a interação, é possível destacarmos algumas características específicas desses dois casos e que transformam a dinâmica do gênero como um todo. O pedido de bibliografia (em rosa) mais uma vez é um agente alteritário que evidencia o lugar da comunicadora, no caso a professora Beth Brait, como enunciadora de autoridade frente ao público, mesmo que virtual. Apesar da chance de tal pergunta não ser propriamente respondida, em virtude de sua complexidade ou pela eventualidade de não ser lida, o sujeito que a enuncia valora que a comunicadora tem experiências suficientes que a conduziriam a responder tal enunciado. Tal traço se percebe pela demarcação do nome da professora (que no momento do comentário era quem estava falando), fazendo-nos compreender que o comentarista não dá acesso aos demais sujeitos tomarem e responderem seu pedido, apesar de que o plano virtual não impeça tal ação. 
O pedido de orientação (em laranja) carrega características similares do que o precede, diferenciando-se por transmitir todas as funções descritas no parágrafo anterior camufladas em um aspecto aparentemente aleatório. O contexto da live acadêmica em si não proporcionou um contexto ou tema para que tal comentário se manifestasse. Todavia, a excelência do trabalho e o reconhecimento histórica e socialmente estabelecido colocam a conferencista no campo de valoração da referência intelectual, provocando no enunciador o ímpeto de reagir a isso em um enunciado que pede orientação ao TCC (Trabalho de Conclusão de Curso).

A última sequência de comentários traz outras duas naturezas alteritárias que se convergem com a live acadêmica em exibição. Eles se caracterizam por construção conjunta do contexto (em cinza) e por enunciado sem rastro aparente (em roxo). Não teceremos análise sobre o comentário azul, por pertencer à categoria requerimento de resposta, já explorada.

Figura 4 - terceiro grupo de enunciados

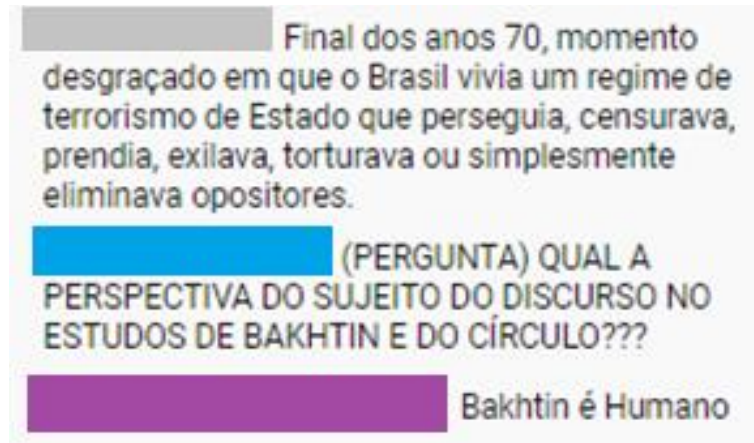

Fonte: Youtube (2020).

A respeito da construção conjunta do contexto (cinza), podemos observar que o espectador adiciona informações de um recorte histórico vivenciado pelo Brasil no dado momento em que as conferencistas também discutem esse período histórico, atrelado ao tema de sua live acadêmica sobre os estudos bakhtinianos. Um aspecto que emerge desse enunciado especificamente é uma tomada de voz enunciadora do espectador. É possível notar tal posicionamento tanto textualmente (a falta de um endereçamento ou de uma construção que sugira interlocução com as comunicadoras) quanto discursivamente (o espectador enuncia seus dados de maneira independente, põe em relevo sua posição emotivo-volitiva sobre o contexto histórico em questão e não necessariamente a partir do que enunciam as conferencistas).

Essa construção conjunta do contexto é, em nossa leitura, um aspecto que transfigura o gênero, quando comparado a sua convenção presencial. Por mais que o comentarista não enuncie em uma tentativa explícita de tomar o lugar de $e u$ da interlocução, amplamente 
reconhecido e referenciado às professoras, o acontecimento discursivo de seu comentário se reflete como tal, colocando momentaneamente em impasse (ainda que sutil) o lugar das comunicadoras e de seu público. Todavia, como já afirmado anteriormente, é necessário reconhecer que a força discursiva do comentário na live acadêmica é significativamente menor se comparada ao lugar enunciativo das conferencistas. Em contrapartida, essa força tem a liberdade de coabitar o espaço, algo não totalmente previsto nos modelos presenciais.

Por fim, o enunciado sem rastro aparente (roxo) é, em nossa perspectiva, uma grande incógnita na análise da live acadêmica. Chamados o caso em questão de enunciado por partirmos da proposição bakhtiniana de que

Todo enunciado - da réplica sucinta (monovocal) do diálogo cotidiano ao grande
romance ou tratado científico - tem, por assim dizer, um princípio absoluto e um fim
absoluto: antes do seu início, os enunciados dos outros; depois do seu término, os
enunciados responsivos de outros (ou ao menos uma compreensão ativamente
responsiva silenciosa do outro ou, por último, uma ação responsiva baseada nessa
compreensão). (BAKHTIN, 2011, p. 275).

Baseando-nos nessa compreensão e em face às temáticas abordadas na live acadêmica, a filiação teórica das comunicadoras e a maioria dos comentários praticados pelos espectadores, podemos afirmar que "Bakhtin é humano" é um enunciado, estabelecido em uma arena discursiva na qual se trata de assuntos correlatos. Ao mesmo tempo, compreendemos esse exemplo como "sem rastro" por não ter sido possível encontrar uma motivação responsiva para sua elaboração. Na impossibilidade de asseverarmos categoricamente que tal comentário seja ou não um enunciado concreto, optamos por conceber a falta de rastro como um silêncio, retomando também Bakhtin (Idem), de que "o enunciado não é uma unidade convencional, mas uma unidade real, precisamente delimitada da alternância dos sujeitos do discurso, a qual termina com a transmissão da palavra ao outro, por mais silencioso que seja o "dixi” percebido pelos ouvintes [como sinal] de que o falante terminou".

\section{Considerações finais}

As considerações e propostas desenvolvidas ao longo deste trabalho concentram-se em promover um entendimento panorâmico sobre uma das tantas mudanças executadas na linguagem e interlocução humana no contexto da pandemia. Apesar de os contextos digitais serem já uma realidade na vida da academia, é inevitável perceber que o isolamento social forçado por questões sanitárias implica novas proposições de gêneros discursivos já institucionalizados, bem como possibilitam formas diferentes de posicionamento alteritário na alternância de sujeitos em interação social.

A respeito da live acadêmica, ainda não é possível afirmar que sua permanência se mantenha em igual frequência em um mundo pós-pandêmico. O primeiro motivo para a 
impossibilidade dessa afirmação se dá no fato de que o presente artigo foi produzido ainda em contexto de pandemia ainda sem perspectivas de término, porém também assumimos a incerteza em virtude desse gênero ter emergido em altas proporções a partir de uma demanda emergencial. Em face de um apelo popular que desaprova a vida integralmente mediada pela esfera virtual, é possível inferir que a estrutura da live acadêmica tenda a se acomodar à convivência com os gêneros orais convencionais, hibridizando-se (como já existe em defesas de mestrado e doutorado com parte da banca em conferência virtual).

$\mathrm{Na}$ live acadêmica como uma plasticidade do gênero discursivo oral comunicação/conferência acadêmica torna-se possível, mais uma vez, reconhecer a relevância dos postulados bakhtinianos na compreensão da linguagem frente às demandas da interação verbal. Ao mesmo tempo, esse tipo de experiência nos coloca frente à inviabilidade de um achatamento demasiado dessa teoria, muitas vezes advindo da didatização excessiva. Sob a ótica da proposta do Círculo, somos capazes de compreender que há um princípio alteritário norteador que reconstrói o gênero às demandas da interação humana, sendo esta uma dinâmica que não se encerra.

Por fim, também é importante considerar a mobilidade do outro na esfera virtual, sobretudo percebido na dinâmica da live acadêmica. Os dados levantados pela análise nos conduzem à tarefa imprescindível de considerar a alteridade como força interdiscursiva que, mesmo aparentemente não visibilizada em todas as suas nuances, movimenta e concretiza os enunciados, provocando-os na dialogicidade da vida.

\section{Referências}

AQUINO, Zilda Gaspar de Oliveira. Gêneros orais, argumentação e ensino de língua portuguesa. Filologia e Linguística portuguesa, v. 17, n. 1, 2015, p. 227-248.

BAKHTIN, Mikhail. Estética da Criação Verbal. São Paulo: Martins Fontes, 2011.

BAKHTIN, Mikhail. Para uma filosofia do ato responsável. Trad. Valdemir Miotello e Carlos Alberto Faraco. São Carlos: Pedro \& João Editores, 2010.

BRAIT, Beth. Olhar e ler: verbo-visualidade em perspectiva dialógica. Bakhtiniana: Revista de Estudos do Discurso, v. 8, p. 43-66, 2013.

BRAIT, Beth; GRILLO, Sheila. A atualidade de Bakhtin: um pensador sobre a humanidade em transformação. Disponível em: https://www.youtube.com/watch?v=dNgUwup9Xww\&t=887s. Último acesso em 19/09/2020. 
FAVERO, Leonor Lopes, ANDRADE, Maria Lúcia da Cunha Victório de Oliveira; AQUINO, Zilda Gaspar de Oliveira. Oralidade e escrita - perspectivas para o ensino de língua materna. São Paulo: Cortez; 1999.

FILHO, Urbano Cavalcante; TORGA, Vânia Lúcia Menezes. Língua, Discurso, Texto, Dialogismo e Sujeito: compreendendo os gêneros discursivos na concepção dialógica, sóciohistórica e ideológica da língua(gem). I Congresso Nacional de Estudos Linguísticos (Ufes), 2011, p. 1-4.

GINZBURG, Carlo. Mitos, Emblemas, Sinais: morfologia e história. São Paulo: Companhia das Letras, 1986.

SENHORAS, Eloi Martins. Coronavírus e educação: análise dos impactos assimétricos. Boca (Boletim de Conjuntura), v. 2, n. 5, p. 128-136, 2020.

MACIEL, Lucas Vinício de Carvalho. Os elementos constitutivos do enunciado em suas relações dialógicas: um exemplo de análise. Linguagem em (Dis)curso - LemD, Tubarão, SC, v. 15, n. 2, p. 249-266, maio/ago. 2015.

MARANHÃO, Romero Albuquerque. Os cientistas sociais no combate ao coronavírus e contra a necropolítica: primeiras batalhas. Boca (Boletim de Conjuntura), v. 2, n. 5, p. 1-14, 2020.

MEDVÉDEV, Pavel. (Círculo de Bakhtin). O método formal nos estudos literários: introdução crítica a uma poética sociológica. Trad. Sheila Grilo e Ekaterina Américo. São Paulo: Contexto, 2012.

SCHMIDT, Beatriz et al. Saúde mental e intervenções psicológicas diante da pandemia do novo coronavírus (COVID-19). Estud. psicol. (Campinas), Campinas, v. 37, e200063, 2020 .

SCHNEUWLY, Bernard., DOLZ, Joaquin. Gêneros orais e escritos na escola. Trad. Roxane Rojo e Glaís S. Cordeiro. Campinas, SP: Mercado das Letras; 2004.

PUZZO, Miriam Bauab. Gênero discursivo, estilo, autoria. Linha D'Água (Online), São Paulo, v. 28, n. 2, p. 172-189, 2015.

ROJO, Roxane; SHNEUWLY, Bernard. As relações oral/escrita nos gêneros orais formais e públicos: o caso da conferência acadêmica. Linguagem Em Discurso. Linguagem em (Dis)curso - LemD, Tubarão, v. 6, n. 3, p. 463-493, set./dez. 2006.

MARCUSCHI, Luiz Antônio. Da fala para a escrita: atividades de retextualização. SP: Cortez, 2001.

RIBEIRO. Pollyane Bicalho. Funcionamento do gênero do discurso. Bakhtiniana, São Paulo, v. 1, n. 3, p. 54-67, 1o sem. 2010.

TECHTUDO. O que é uma live? Saiba tudo sobre as transmissões ao vivo da internet. Disponível em: https://www.techtudo.com.br/noticias/2020/03/o-que-e-uma-live-saiba-tudosobre-as-transmissoes-ao-vivo-na-internet.ghtml. Último acesso em 19/09/2020.

TRAVAGLIA, Luiz Carlos et al. Gêneros orais - conceituação e caracterização. Anais do SILEL. Volume 3, Número 1. Uberlândia: EDUFU, 2013. 
Recebido em 11 de julho de 2021. Aceito em 11 de novembro de 2021. 